\title{
Base Metal-Pt Alloys: A General Route to High Selectivity and Stability in the Production of Biofuels from HMF
}

\author{
Jing Luo ${ }^{\mathrm{a}}$, Jennifer D. Lee ${ }^{\mathrm{b}}$, Hongseok Yun ${ }^{\mathrm{b}}$, Cong Wang ${ }^{\mathrm{a}}$, Matteo Monai ${ }^{\mathrm{c}}$, Christopher B. \\ Murray $^{\mathrm{b}}$, Paolo Fornasiero ${ }^{\mathrm{c}}$ and Raymond J. Gorte ${ }^{\mathrm{a}, *}$ \\ ${ }^{a}$ Department of Chemical \& Biomolecular Engineering, University of Pennsylvania \\ Philadelphia, PA 19104, United States \\ ${ }^{\mathrm{b}}$ Department of Chemistry, University of Pennsylvania \\ Philadelphia, PA 19104, United States \\ ${ }^{c}$ Department of Chemical and Pharmaceutical Sciences, ICCOM-CNR and INSTM Trieste \\ research unit, University of Trieste \\ Trieste, 34127, Italy
}

\begin{abstract}
Hydrodeoxygenation (HDO) of 5-hydroxymethylfurfural (HMF) was examined over well-defined and uniform, $\mathrm{Pt}-\mathrm{Ni}, \mathrm{Pt}-\mathrm{Zn}$ and $\mathrm{Pt}-\mathrm{Cu}$ alloyed nanocrystals (NCs) supported on carbon, at 33 bar and between 160 and $200{ }^{\circ} \mathrm{C}$. Pt-Ni alloy catalysts were prepared in three different $\mathrm{Pt}$ :Ni ratios, $\mathrm{Pt}_{6} \mathrm{Ni}, \mathrm{Pt}_{3} \mathrm{Ni}$, and $\mathrm{PtNi}$. While all of the $\mathrm{Pt}-\mathrm{Ni}$ alloys were more selective for producing 2,5-dimethylfuran (DMF) than were $\mathrm{Pt}$ or $\mathrm{Ni}$ monometallic catalysts, the $\mathrm{Pt}_{3} \mathrm{Ni}$ catalyst was superior to the other compositions, exhibiting a yield of $98 \%$ due to its optimum surface composition. Similarly high yields were obtained on catalysts prepared from $\mathrm{Pt}_{2} \mathrm{Zn}$ and $\mathrm{PtCu}$ NCs. Possible reasons are given for why each of the Pt-alloy catalysts is highly selective.
\end{abstract}

Keywords: 5-hydroxymethylfurfural, hydrodeoxygenation, 2,5-dimethyl furan, nanocrystal, bimetallic catalyst 
E-mails:

jingluo@seas.upenn.edu

gorte@seas.upenn.edu

Address:

Department of Chemical and Biomolecular Engineering, University of Pennsylvania,

311A Towne Building, 220 S. $33^{\text {rd }}$ Street,

Philadelphia, PA 19104, USA

Phone: 215-898-8351

Fax: 215-573-2093

*Corresponding Author:

Raymond J. Gorte

gorte@ seas.upenn.edu 


\section{INTRODUCTION}

The conversion of biomass into fuels and other petrochemical replacements is receiving an ever increasing amount of attention as concerns about sustainability grow. Among the more important reactions for utilizing biomass is the hydrodeoxygenation (HDO) of 5hydroxymethylfurfural (HMF) to 2,5-dimethylfuran (DMF). HMF is produced by the acidcatalyzed dehydration of C-6 sugars [1-3] but is too unstable to be used directly in most applications due to its high degree of chemical functionality. The conversion of HMF to DMF consumes relatively little hydrogen (HMF: $\mathrm{H}_{2}$ molar ratio 1:3) and results in a product that can be used directly as a fuel additive. DMF can also be reacted with ethylene to produce $\mathrm{p}$-xylene in high yields [4], demonstrating that an important chemical feedstock can be produced from renewable resources.

Achieving high selectivities (> 90\%) in the reaction of HMF to DMF remains a problem. Possibly because the reaction products depend strongly on reactor conditions, a wide range of selectivities have been reported by the various groups which have studied the problem [5-7], sometimes for similar catalysts. However, for monometallic catalysts, yields are generally below $60 \%$. Work from our groups has shown that the HDO of HMF is a series reaction over most carbon-supported, monometallic catalysts, with DMF forming as an intermediate product that can further react [8]. On carbon-supported $\mathrm{Pt}, \mathrm{Pd}, \mathrm{Ir}, \mathrm{Ni}, \mathrm{Ru}$, and Co catalysts, DMF is converted to the undesired ring-opened (e.g. 2-hexanone, 2,5-hexanedione) and ring-hydrogenated (e.g. 2,5-dimethyltetrahydrofuran, DMTHF) products under the conditions required to react HMF to DMF [8]. Because of this, the maximum yield of a given catalyst depends on the relative rates of HMF converting to DMF and of DMF converting to other products.

There is considerable evidence that bimetallic catalysts can be more selective for HDO reactions. For example, in the gas-phase reaction of furfural, $\mathrm{Ni}-\mathrm{Fe}$ catalysts were found to exhibit good selectivity to methylfuran under conditions that resulted in the decarbonylation product, furan, over the monometallic Ni catalyst [9]. In another example involving the reaction of HMF, Wang et al. [10] reported that catalysts based on Pt-Co nanoparticles, encapsulated in hollow carbon spheres, could give DMF yields as high as $98 \%$. We have recently confirmed this result on carbon-supported Pt-Co nanocrystals (NCs), without the carbon hollow-spheres, and further showed that the bimetallic catalysts exhibit much better stability than the monometallic 
catalysts [11]. The high selectivity of the Pt-Co catalysts resulted from the fact that DMF is unreactive over the bimetallic catalyst.

It is not entirely clear why the bimetallic catalysts are more selective for HDO and the reasons may vary with the particular alloy or reactor conditions. Several studies have argued the high selectivities of the studied bimetallic catalysts is due to the oxophilicity of the secondary metal [9,12-14]. For example, Resasco and coworkers [9] observed that NiFe catalysts showed superior selectivity compared to $\mathrm{Ni}$ for the reaction of furfural to methyl furan. Their theoretical calculations indicated that the oxophilic nature of Fe stabilizes the $\eta^{2}(C, O)$ configuration of the aldehyde carbonyl, weakening the $\mathrm{C}-\mathrm{O}$ bond and suppressing the formation of acyl intermediates that undergo decarbonylation [9]. High selectivities have also been reported for HDO reactions over Pd-Cu alloys [15]. In this example, the HDO selectivities improved from $20 \%$ for a Pd-only catalyst to $75 \%$ for the Pd-Cu alloy. Although $\mathrm{Cu}$ is not oxophilic, DFT calculations suggested that $\mathrm{Cu}$ atoms at the surface repel the aromatic furan ring [16], causing furfural to preferentially adsorb in an $\eta^{1}(\mathrm{O})$-aldehyde configuration via the carbonyl oxygen. Such an orientation of the furan ring prevents side reactions on the ring itself $[9,15,16]$. Finally, recent work by some of us on the Pt-Co system showed that Co tends to form a $\mathrm{CoO}_{\mathrm{x}}$ shell on a Pt-rich core and that this oxide layer prevents interactions between the Pt and the furan ring, enhancing DMF yields from HDO of HMF [11].

In the present work, we examined the catalytic properties of other Pt alloys, including carbon-supported Pt-Ni, Pt-Zn, and Pt-Cu alloyed NCs prepared by solvothermal methods, in order to determine whether Pt-Co is unique among the Pt alloys in providing high selectivities for HDO of HMF. While Ni is catalytically similar to $\mathrm{Co}, \mathrm{Zn}$ and $\mathrm{Cu}$ have properties that contrast sharply with that of Co and provide a test for the properties required for high selectivities (>95\%). Surprisingly, each of the alloys exhibited superior selectivities compared to the monometallic catalysts. By using bimetallic, NCs catalysts with highly uniform compositions and monodispersities, we were also able to demonstrate that there are optimal compositions for the alloy catalysts.

\section{EXPERIMENTAL}

\section{Catalyst Synthesis}

Chemicals 
The following chemicals were used in the synthesis of the metal NCs: Nickel (II) acetate tetrahydrate $\left(\mathrm{Ni}(\mathrm{ac})_{2} \cdot 4 \mathrm{H}_{2} \mathrm{O}\right.$, Sigma-Aldrich, $\left.98 \%\right)$, platinum (II) acetylacetonate $\left(\mathrm{Pt}(\mathrm{acac})_{2}\right.$, Acros, 98\%), nickel (II) acetylacetonate (Ni(acac) 2 , Acros Organics, $96 \%$ ), copper (II) acetylacetonate $\left(\mathrm{Cu}(\mathrm{acac})_{2}\right.$, Sigma-Aldrich, $\geq 99.9 \%$ ), zinc (II) acetylacetonate ( $\mathrm{Zn}(\mathrm{acac})_{2}$, Acros Organics, 25 \% Zn), 1,2-hexadecanediol (HDD, Sigma-Aldrich, 90 \%), tri-n-octylamine (TOA, Acros Organics, $97 \%$ ), oleylamine (OLAM, Sigma-Aldrich, $70 \%$ ), oleic acid (OLAC, SigmaAldrich, $90 \%$ ), and trioctylphosphine (TOP, Sigma-Aldrich, $97 \%$ ), borane, tert-butylamine complex, (BTB, Strem Chemicals, 97 \%), diphenyl ether (DPE, Sigma-Aldrich, 99 \%) and 1,2dichlorobenzene (DCB, Acros Organics, $99 \%$ ). Nickel(II) nitrate hexahydrate $\left(\mathrm{Ni}\left(\mathrm{NO}_{3}\right)_{2} \cdot 6 \mathrm{H}_{2} \mathrm{O}\right.$, Alfa Aesar, 98\%), Zinc(II) nitrate hexahydrate $\left(\mathrm{Zn}\left(\mathrm{NO}_{3}\right)_{2} \cdot 6 \mathrm{H}_{2} \mathrm{O}\right.$, Alfa Aesar, 99\%), Copper(II) nitrate trihydrate $\left(\mathrm{Cu}\left(\mathrm{NO}_{3}\right)_{2} \cdot 3 \mathrm{H}_{2} \mathrm{O}\right.$, Alfa Aesar, 98\%), and Cobalt(II) nitrate hexahydrate $\left(\mathrm{Co}\left(\mathrm{NO}_{3}\right)_{2} \cdot 6 \mathrm{H}_{2} \mathrm{O}\right.$, Aldrich, 99\%).

\section{Synthesis of $\mathrm{Pt}_{6} \mathrm{Ni}$ and $\mathrm{PtNi} \mathrm{NCs}$}

The $\mathrm{Pt}_{6} \mathrm{Ni}$ and $\mathrm{PtNi} \mathrm{NCs}$ were synthesized using a scaled-up method reported previously [17]. For the $\mathrm{Pt}_{6} \mathrm{Ni} \mathrm{NCs}, \mathrm{Ni}(\mathrm{ac})_{2} \cdot 4 \mathrm{H}_{2} \mathrm{O}(0.33 \mathrm{mmol})$ and HDD $(1.15 \mathrm{mmol})$ were dissolved in a solution of DPE $(40 \mathrm{~mL})$, OLAM $(0.8 \mathrm{~mL})$, and OLAC $(0.8 \mathrm{~mL})$. The reaction mixture was kept at $80{ }^{\circ} \mathrm{C}$ for $30 \mathrm{~min}$ under vacuum and then heated to $200{ }^{\circ} \mathrm{C}$ under a nitrogen atmosphere. $\mathrm{Pt}(\mathrm{acac})_{2}(0.67 \mathrm{mmol})$, dissolved in DCB $(2.4 \mathrm{~mL})$, was injected into this mixture at $200{ }^{\circ} \mathrm{C}$. The resulting solution was kept at $200{ }^{\circ} \mathrm{C}$ for $1 \mathrm{~h}$ before cooling to room temperature. The resulting NCs were then purified by precipitation with ethanol and centrifugation at $8000 \mathrm{rpm}$ for $5 \mathrm{~min}$. The precipitate was washed twice with hexane/ethanol (1:3) mixtures before the final NCs were dispersed in hexane. The same procedure was used to synthesize PtNi NCs, except that the amounts of $\mathrm{Ni}(\mathrm{ac})_{2} \cdot 4 \mathrm{H}_{2} \mathrm{O}(2 \mathrm{mmol})$ and OLAC $(1.0 \mathrm{~mL})$ were adjusted. Also, after the washing steps, the PtNi NCs were re-dispersed in hexane and size-selective precipitation was performed [18] .

Synthesis of $\mathrm{Pt}_{3} \mathrm{Ni} \mathrm{NCs}$

To synthesize $\mathrm{Pt}_{3} \mathrm{Ni} \mathrm{NCs}, \mathrm{Ni}(\mathrm{acac})_{2}(0.4 \mathrm{mmol})$ and $\mathrm{Pt}(\mathrm{acac})_{2}(0.4 \mathrm{mmol})$ were dissolved in a solution of TOA $(40 \mathrm{~mL})$, OLAM $(5.44 \mathrm{~mL})$, OLAC $(1.28 \mathrm{~mL})$, and TOP $(0.45 \mathrm{~mL})$. The reaction mixture was kept under vacuum at $70{ }^{\circ} \mathrm{C}$ for $30 \mathrm{~min}$, then heated to $330{ }^{\circ} \mathrm{C}$ under a nitrogen atmosphere. After $30 \mathrm{~min}$, the reaction mixture was cooled to room temperature and purified by precipitation with a mixture of isopropanol and ethanol. After being centrifuged at 
$8000 \mathrm{rpm}$ for $2 \mathrm{~min}$, the precipitate was washed twice with hexane/ethanol (1:3) mixtures. Finally, the NCs were dispersed in hexane.

\section{Synthesis of PtCu and $\mathrm{Pt}_{2} \mathrm{Zn} \mathrm{NCs}$}

$\mathrm{PtCu}$ and $\mathrm{Pt}_{2} \mathrm{Zn}$ NCs were synthesized by modifying a previously reported method [19] . For PtCu NCs, Pt(acac) 2 (0.4 mmol), Cu(acac) 2 (0.4 mmol), and BTB (1.1 mmol) were dissolved in OLAM $(20 \mathrm{~mL})$. The reaction mixture was kept under vacuum at $80{ }^{\circ} \mathrm{C}$ for $30 \mathrm{~min}$ before heating to $300{ }^{\circ} \mathrm{C}$ at a rate of $5^{\circ} \mathrm{C} \mathrm{min}^{-1}$. After $1 \mathrm{~h}$, the reaction mixture was cooled to room temperature. Purification of the NCs was achieved by addition of isopropanol, followed by centrifugation at $8000 \mathrm{rpm}$ for $2 \mathrm{~min}$. The precipitate was washed three times with hexane/ethanol (1:3) mixtures and the final NCs were dispersed in hexane. For $\mathrm{Pt}_{2} \mathrm{Zn} \mathrm{NCs}$, $\mathrm{Pt}(\mathrm{acac})_{2}(0.5 \mathrm{mmol}), \mathrm{Zn}(\mathrm{acac})_{2}(0.5 \mathrm{mmol})$ and BTB $(1.1 \mathrm{mmol})$ were dissolved in OLAM (20 $\mathrm{mL})$. The reaction conditions and purification steps were the same as those for PtCu NCs synthesis.

\section{NC Characterization}

The TEM images of NCs were collected on a JEOL JEM-1400 microscope operating at $120 \mathrm{kV}$ and HRTEM on a JEOL JEM-2100 operating at $200 \mathrm{kV}$. Particle-size distributions were determined by small-angle X-ray scattering (SAXS) performed at Penn's Multi-Angle X-ray Scattering Facility and analyzed by Datasqueeze software [20]. Sample collection time was $1 \mathrm{~h}$. The average sizes and size distributions were presented as (diameter) \pm (standard deviation) $\mathrm{nm}$. The elemental composition and concentration of NCs were determined by Inductively Coupled Plasma-Optical Emission spectrometry (ICP-OES) performed on a Spectro Genesis spectrometer with a concentric nebulizer. Powder X-ray diffraction (XRD) patterns were collected in the $2 \theta$ range between $20^{\circ}$ and $80^{\circ}$ on a Rigaku Smartlab high-resolution diffractometer with $\mathrm{Cu} \mathrm{K} \alpha$ radiation $(\lambda=0.15416 \mathrm{~nm})$.

\section{Preparation of Supported NCs}

To prepare catalysts from the NCs, the NCs, dispersed in hexane, were mixed with carbon powder (Cabot, Vulcan XC72R) to a loading of 10-wt\% metal. After sonication for 15 min, the solution was centrifuged at $6000 \mathrm{rpm}$ for $1 \mathrm{~min}$. The supernatant was removed and the precipitate was washed twice with isopropanol, followed by centrifugation. After drying each sample in a vacuum oven overnight at $50{ }^{\circ} \mathrm{C}$, the samples were first treated with an $\mathrm{O}_{2}$ plasma 
cleaner (18 W, Harrick Plasma) for $15 \mathrm{~min}$, then transferred for $1 \mathrm{~min}$ into a muffle furnace that had been preheated to $500{ }^{\circ} \mathrm{C}[21]$.

Synthesis of Conventional Ni/C, Co/C, Cu/C, and Zn/C Catalysts

The $10-w t \% ~ N i / C, C o / C, C u / C$ and $\mathrm{Zn} / \mathrm{C}$ catalyst in this study were prepared by impregnation, using an identical procedure that is consistent with those in previous studies [8]. The $\mathrm{Ni}, \mathrm{Zn}, \mathrm{Cu}$ and $\mathrm{Co}$ precursors were $\mathrm{Ni}\left(\mathrm{NO}_{3}\right)_{2} \cdot 6 \mathrm{H}_{2} \mathrm{O}, \mathrm{Zn}\left(\mathrm{NO}_{3}\right)_{2} \cdot 6 \mathrm{H}_{2} \mathrm{O}, \mathrm{Cu}\left(\mathrm{NO}_{3}\right)_{2} \cdot 3 \mathrm{H}_{2} \mathrm{O}$, and $\mathrm{Co}\left(\mathrm{NO}_{3}\right)_{2} \cdot 6 \mathrm{H}_{2} \mathrm{O}$, respectively. Each metal precursor was firstly dissolved in a water/ethanol $(5: 1)$ solution and then mixed with carbon black (Vulcan XC-72R). After drying the catalyst at room temperature, the resulting powder was heated in flowing $\mathrm{He}$ to $500^{\circ} \mathrm{C}$ for $6 \mathrm{~h}$, using a heating ramp of $3{ }^{\circ} \mathrm{C} \mathrm{min}{ }^{-1}$. The dried powders were reduced by flowing a $5 \% \mathrm{H}_{2} / \mathrm{He}$ mixture over the catalysts at $60 \mathrm{mLmin}^{-1}$ while ramping the temperature at $2{ }^{\circ} \mathrm{C} \min ^{-1}$ to $400{ }^{\circ} \mathrm{C}$, followed by heating to $500{ }^{\circ} \mathrm{C}$ with heating ramp of $1{ }^{\circ} \mathrm{C} \mathrm{min}{ }^{-1}$. The catalysts were then held at this temperature for $2 \mathrm{~h}$.

\section{Reaction Measurements}

The liquid-phase HDO of HMF was performed in a continuous flow reactor which has been described elsewhere [8,22]. The reactor was a stainless-steel tube, $20 \mathrm{~cm}$ long and with a 4.6-mm ID. The typical catalyst loading was $0.05 \mathrm{~g}$. For experiments requiring lower space times, the catalyst was diluted with additional carbon while keeping the total reactor loading at $0.05 \mathrm{~g}$. The catalyst was packed in the middle portion of the tubular reactor and held by glass wool. To prevent the catalyst from being pushed from the center of the tube, an inert glass tube was placed downstream from the catalyst bed. The liquid feed, a mixture of $1.0 \mathrm{~g} \mathrm{HMF}(99 \%$, Sigma-Aldrich) and $100 \mathrm{~mL}$ of 1-propanol (Fisher Scientific), was introduced into the reactor using an HPLC pump (Series I+, Scientific Systems Inc.), which was also used to measure the total pressure in the reactor. The gas feed, $\mathrm{H}_{2}$ (UHP grade, Airgas), was co-fed into the reactor through 0.002-inch ID capillary tubing (Valco Instruments, Inc.) and the gas flow rate was controlled by adjusting the pressure drop across the capillary tubing. A bubble meter at the reactor exit was used periodically to check the $\mathrm{H}_{2}$ flow rates. The liquid flow rates could be varied from 0.02 to $0.2 \mathrm{~mL} \mathrm{~min}^{-1}$, while the $\mathrm{H}_{2}$ flow rates were 2 to $20 \mathrm{~mL} \mathrm{~min}^{-1}$ (STP). The ratio of the liquid and gas flow rates was kept constant in all experiments. A back-pressure regulator (KPB series, Swagelok) was placed at the reactor exit in order to control the pressure within the reactor. 
Before carrying out reactions, the catalysts were pretreated at $250^{\circ} \mathrm{C}$ in 1 -bar, flowing $\mathrm{H}_{2}$ for $30 \mathrm{~min}$. The liquid products were collected and analysis was performed using syringe injection into a GC-MS (QP-5000, Shimadzu), equipped with a capillary column (HP-Innowax, Agilent Technologies). The gas-phase products were also examined but were found to consist of only $\mathrm{H}_{2}$ and solvent vapor. Quantification of the major products was accomplished by calibration with standard solutions of HMF, DMF, DMTHF, 2-hexanone, 2-hexanol, and 2,5-hexandione (all purchased from Sigma Aldrich). The GC sensitivities for furanic-intermediate products were assumed to be the same as that for HMF, while the GC sensitivities for open-ring ether products were assumed to be the same as that of 2-hexanone. Based on repeated measurements, the uncertainty in the conversions and yields was less than 5\% in all cases, and the carbon balances were above $95 \%$ in all cases. The measurement times for each experiment were approximately 4 $\mathrm{h}$ and most of the data used in this manuscript were taken 40 to $60 \mathrm{~min}$ after starting the reaction. For the conditions of this study, there was no reaction in the absence of a catalyst. The space times $(\mathrm{W} / \mathrm{F})$ in this work were given as the weight of the metal catalyst divided by the volumetric flow rates of the liquid.

\section{RESULTS}

\section{Nanocrystal Catalyst Characterization}

Nearly monodisperse Pt-based alloyed NCs with various compositions were synthesized by solvothermal synthesis, which enabled us to investigate the composition dependent catalytic behavior of the bimetallic NCs. TEM images of the $\mathrm{Pt}_{6} \mathrm{Ni}, \mathrm{Pt}_{3} \mathrm{Ni}$ and $\mathrm{PtNi} \mathrm{NCs}$ are shown in Figure 1a)-1c) and indicate that, in each case, the particles are uniform and spherical in shape. Based on the small-angle X-ray scattering (SAXS) data fitted to Rayleigh function (Figure 1d)), the average sizes and size distributions of the $\mathrm{Pt}_{6} \mathrm{Ni}, \mathrm{Pt}_{3} \mathrm{Ni}$, and $\mathrm{PtNi} \mathrm{NCs}$ were 3.0 0 0.4, 3.0 \pm 0.6 and $6.0 \pm 0.8 \mathrm{~nm}$, respectively. As shown in Figure 1e), the XRD patterns for each of the NCs showed a face-centered cubic (fcc) crystal structure, and shifts to higher angles in the peaks at $2 \theta$ were observed for $\mathrm{Pt}_{6} \mathrm{Ni}$ and PtNi NCs, compared with the pure Pt NCs. This results from a contraction of the lattice based on the Vegard's law [23] and is a good indication that the NCs are well-mixed bimetallics. In the case of $\mathrm{Pt}_{3} \mathrm{Ni} \mathrm{NCs}$, the only observed $2 \theta$ peak corresponds to the (111) plane. The absence of additional peaks suggests either polycrystallinity or the presence of a high concentration of defects, as is often seen with NC systems [24]. There was essentially 
no change in the morphology or size of the NCs following their addition to the carbon support and their treatment to remove the ligands by $\mathrm{O}_{2}$ plasma and thermal annealing. This is demonstrated by the TEM images shown in Figures S1a) to S1c).

The Pt-Ni NC catalysts also exhibited good stability under HDO reaction conditions. Figure 2 shows TEM images of the catalysts based on $\mathrm{Pt}_{6} \mathrm{Ni}$ NCs before (Figure $2 \mathrm{a}$ )) and after (Figure 2b)) $5 \mathrm{~h}$ of HDO reaction. The thermal stability of NC catalysts was further confirmed by SAXS measurements (Figure 2c)). By subtracting out the scattering from carbon support (black curve) and performing fitting with Rayleigh function, the average sizes of $\mathrm{Pt}_{6} \mathrm{Ni} / \mathrm{C}$ before (green curve) and after (blue curve) the functional testing were $4.1 \pm 0.8$ and $4.1 \pm 0.7 \mathrm{~nm}$, respectively. The results from SAXS measurements indicate no change in the size of the NCs consistently with TEM observations. The XRD patterns (Figure 2d)) measured before (green curve) and after (blue curve) the catalyst was exposed to the reaction environment also indicated that there was no phase transformation from disordered fcc to ordered face-centered tetragonal (fct) structure. The carbon support was measured as a control (black curve) and peaks near $25^{\circ}$ and $43^{\circ}$ correspond to graphite (002) and diamond (111) planes for Vulcan carbon supports [25]. The thermal stability of crystal structure makes it possible to exclude a contribution from structural ordering on the catalytic performance.

Similar characterization studies were performed with the catalysts prepared from $\mathrm{PtCu}$ and $\mathrm{Pt}_{2} \mathrm{Zn}$ NCs, with TEM images shown in Figure $3 \mathrm{a}$ ) to $3 \mathrm{~b}$ ). The addition of a stronger reducing agent (BTB) resulted in smaller NCs than the ones prepared without BTB, which is consistent as reported [19]. XRD patterns of the as-synthesized $\mathrm{PtCu}$ and $\mathrm{Pt}_{2} \mathrm{Zn}$ NCs also showed fcc structure (Figure 3d)). Based on SAXS data fitted to Rayleigh function (Figure 3c)), the average sizes and size distributions of the $\mathrm{PtCu}$ and $\mathrm{Pt}_{2} \mathrm{Zn}$ NCs are $6.6 \pm 1.2$ and 2.6 $\pm 0.6 \mathrm{~nm}$, respectively. The catalyst characterizations discussed above indicate that the NCs synthesized by solvothermal methods were excellent subjects to study the bimetallic catalyst composition dependent HDO of HMF.

\section{Hydrodeoxygenation of HMF in a continuous flow reactor}

In previous studies, we showed that the HDO reaction for HMF in several alcohol solvents is a series reaction, with products forming as shown in Scheme 1 [8,22]. The HMF (A) is first converted to a group of partially hydrogenated intermediate species (B), including 2- 
propoxymethyl-5-furanmethanol (ether-furfuryl alcohol, or EFA), 2-propoxymethyl-5methylfuran (ether-methyl furan, or EMF), 5-methylfurfural (MF), 2-hydroxylmethyl-5methylfuran (HMMF), 2,5-bis(hydroxymethyl)furan (BHMF), and 2,5-bis(propoxymethyl)furan (BEF). All these intermediates can react further to form DMF $(C)$, which in turn reacts to overhydrogenated products (D), such as DMTHF 2-hexanone, 2-hexanol, 2,5-hexanedione, and their etherification derivatives, 1-propoxy-1-methylpentane (2-propoxyhexane) and 1,4-dipropoxy1,4-dimethylbutane (2,5-dipropoxyhexane). All of the studied monometallic catalysts, including carbon-supported $\mathrm{Pt}, \mathrm{Pd}, \mathrm{Ir}, \mathrm{Ru}, \mathrm{Co}$, and $\mathrm{Ni}$, were found to exhibit relatively poor selectivity for DMF formation $[8,11,22]$. DMF yields varied with the particular metal catalyst and the reaction conditions but were typically less than about $50 \%$. The products formed by the further reaction of DMF also varied with the metal catalyst, with Pt tending to form open-ring products, primarily 2-hexanone and 2-propoxyhexanone [8].

Figure 4 shows a comparison of HMF conversions and DMF yields at $180{ }^{\circ} \mathrm{C}$ and 33 bar total pressure for conventional $\mathrm{Ni} / \mathrm{C}, \mathrm{Co} / \mathrm{C}$, and $\mathrm{Cu} / \mathrm{C}$ catalysts with 10 -wt $\%$ metal. Results for $\mathrm{Ni} / \mathrm{C}$ and $\mathrm{Co} / \mathrm{C}$ are similar to what was reported previously [8]. Both catalysts show high conversions, over 50\%, for even short residence times; and the DMF yield goes through a maximum of slightly more than $50 \%$ with increasing space time, decreasing with longer space times. The detailed product distributions are reported elsewhere [8], but the major overhydrogenated product for both metals was 2,5-hexandione. By contrast, the $\mathrm{Cu} / \mathrm{C}$ was much less active, with a maximum conversion of less than $40 \%$ at the longest space time studied. The only products formed over the $\mathrm{Cu} / \mathrm{C}$ catalyst were those in the $\mathrm{B}$ group of Scheme 1, including $\mathrm{MF}$, HMMF and BEF, with yields listed in Table S1. The low HDO activity observed over Cu agrees with previous literature hydrogenation reactions of furfural over $\mathrm{Cu}$ catalysts, which shows that the reaction over $\mathrm{Cu}$ tends to stop with formation of furfuryl alcohol [15]. Zn/C catalysts did not show any activity for HDO of HMF under the conditions of this study.

The bimetallic catalyst, Pt-Co, can be highly selective for production of DMF, with $98 \%$ yield for optimized metal compositions and reaction conditions [11]. The high selectivity in that case was the result of DMF being unreactive, so that the sequential reaction stopped at DMF. Furthermore, because both Pt and Co are able to catalyze the reaction of DMF to overhydrogenated products, exceptional selectivity was only observed when the bimetallic NCs were prepared by solvothermal synthesis. Bimetallic catalysts prepared by conventional infiltration of 
the metal salts were less selective due to non-uniformities in the local composition of the metal particles.

To determine how other bimetallic catalysts would perform in comparison to Pt-Co, similar experiments were performed over the $\mathrm{Pt}-\mathrm{Ni}, \mathrm{Pt}-\mathrm{Cu}$, and $\mathrm{Pt}-\mathrm{Zn}$ bimetallic catalysts. Figure 5 reports the HMF conversion and product yields as a function of space time for the three Pt$\mathrm{Ni} / \mathrm{C}$ catalyst at $160{ }^{\circ} \mathrm{C}$ and 33 bar. The results are qualitatively similar for all three Pt-Ni catalysts, although the $\mathrm{Pt}_{3} \mathrm{Ni} / \mathrm{C}$ catalyst in Figure $5 \mathrm{~b}$ ) showed somewhat lower conversions. At a space time of $0.5 \mathrm{~g} \cdot \mathrm{min} \mathrm{mL}^{-1}$, the conversion over $\mathrm{Pt}_{3} \mathrm{Ni} / \mathrm{C}$ was around $85 \%$, while the conversions on the other two Pt-Ni catalysts were over 95\%. In general, HMF conversion increased steadily with space time, while partially hydrogenated products (B group) yield diminished in favor of DMF formation. Except for $\mathrm{Pt}_{3} \mathrm{Ni} / \mathrm{C}$, DMF yield reached a value of 8090\% before decreasing due to over-hydrogenated products (D group) formation. The fact that the D products form at the same space times for which DMF yields begin to decrease suggests that they are formed from DMF. The major $\mathrm{D}$ product observed with the $\mathrm{Pt}_{6} \mathrm{Ni} / \mathrm{C}$ catalyst was 2hexanone, the same major product formed on Pt catalysts [8,22], while with $\mathrm{PtNi} / \mathrm{C} 2,5-$ hexandione was observed, which was also the primary product formed on Ni/C catalysts [8]. Interestingly, no over-hydrogenated products were observed on the $\mathrm{Pt}_{3} \mathrm{Ni} / \mathrm{C}$ catalyst for even the highest space time examined. A more detailed analysis of the B and D compounds yield is given in the Supplemental Information, Table S2a.

Because the conversions for the $\mathrm{Pt}_{3} \mathrm{Ni} / \mathrm{C}$ were low at $160{ }^{\circ} \mathrm{C}$, additional measurements were performed on this catalyst at $200{ }^{\circ} \mathrm{C}$, with results reported in Figure 6. At this temperature, the conversions of HMF were much higher. Furthermore, DMF yields reached $98 \%$ at the higher space times. It is not likely that the higher yields are due to the increase in temperature. In addition to the fact that previous work indicated that selectivities are not very different between 100 and $200{ }^{\circ} \mathrm{C}[11,22]$, one would expect the reaction of DMF to over-hydrogenated products to increase with temperature. The maximum in the yield as a function of space time in Figure 6 is clearly less steep than that found for $\mathrm{Pt}_{6} \mathrm{Ni} / \mathrm{C}$ and $\mathrm{PtNi} / \mathrm{C}$ catalysts. Furthermore, the $\mathrm{Pt}_{3} \mathrm{Ni} / \mathrm{C}$ catalyst was remarkably stable. There was no observable change in either the conversion or the DMF yield over a period of at least $5 \mathrm{~h}$ on the $\mathrm{Pt}_{3} \mathrm{Ni} / \mathrm{C}$ catalyst, while significant changes in both were observed on Pt/C and Ni/C catalysts. The data in Figures 5 and 6 therefore indicate that the 
Pt-Ni catalysts are more selective and stable than their monometallic counterparts and that there is an optimum $\mathrm{Pt}$ :Ni ratio.

Catalysts based on Pt-Zn and Pt-Cu bimetallic NCs were also investigated, with results shown in Figures 7 and 8. Because these catalysts were also less active than $\mathrm{Pt} / \mathrm{C}$, reactions were carried out at $200{ }^{\circ} \mathrm{C}$ and 33 bar. The results for $10-\mathrm{wt} \% \mathrm{Pt}_{2} \mathrm{Zn} / \mathrm{C}$ in Figure 7 are very similar to results for $\mathrm{Pt}_{3} \mathrm{Ni} / \mathrm{C}$, although the rates were slightly lower. Again, DMF yields as high as $98 \%$ were achieved at high space time, with negligible production of over-hydrogenated products. Similar performance was observed over the $\mathrm{PtCu} / \mathrm{C}$ catalyst, Figure 8, with DMF yields again reaching 96\%. However, alloying the $\mathrm{Pt}$ with $\mathrm{Cu}$ did significantly decrease the rates.

\section{DISCUSSION}

The results of the present study clearly demonstrate that the catalysts formed by alloying Pt with a number of metals can significantly increase the yields for the HDO reaction of HMF to DMF. In all cases, the increased yields result from a decreased reactivity of DMF to overhydrogenated products. As pointed out in the Introduction, the alloying metals appear to do this in different ways but the net result in each case is that the alloying metal prevents the furan ring from lying down on the catalyst surface. With Pt-Co alloys, the furan ring is prevented from lying down on the surface by a "honey-comb", $\mathrm{CoO}_{\mathrm{x}}$ overlayer on the $\mathrm{Pt}$ [11]. Since Ni is more easily reduced than $\mathrm{Co}$, the effect of $\mathrm{Ni}$ on the bonding of the furans on the Pt-Ni alloys is likely due to the oxophilicity of the $\mathrm{Ni}$, similar to what was reported for the effect of $\mathrm{Fe}$ on $\mathrm{Ni}-\mathrm{Fe}$ alloy catalysts [9]. With $\mathrm{Cu}$ and $\mathrm{Zn}$, the role of the alloying metals may be to change the Pt ensemble size or otherwise change the way the DMF bonds to the metal surfaces $[13,15]$.

The selective alloy catalysts were also more stable. Previous work with monometallic catalysts based on $\mathrm{Pt}, \mathrm{Ni}$, and $\mathrm{Co}$ indicated that each showed significant deactivation over a period of three hours. Furthermore, deactivation appears to have been caused by coking, since the deactivation rates correlated with the carbon balances in the experiment. In the present study, there was no observable deactivation of a $\mathrm{Pt}_{3} \mathrm{Ni} / \mathrm{C}$ catalyst, consistent with what was also

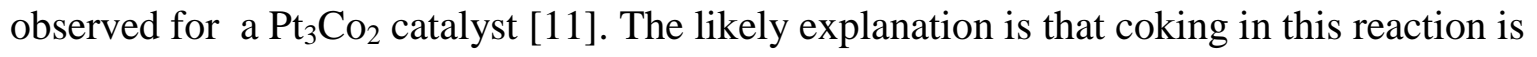
caused by the over-hydrogenated products. The over-hydrogenated products include di-ketones, which tend to be highly reactive. 
With Pt-Ni and Pt-Co alloys, compositional uniformity of the catalyst is critical. Monometallic catalysts based on $\mathrm{Pt}, \mathrm{Ni}$, and $\mathrm{Co}$ are not selective because all three metals will catalyze the reaction of DMF to over-hydrogenated products [8]. Furthermore, the selectivity of the Pt-Ni and Pt-Co bimetallic catalysts depends on the Pt:Co [11] and Pt:Ni ratios. Synthesis of bimetallic catalysts by conventional methods in which the support is infiltrated with metal salts is not able to produce this uniformity, which is the reason we prepared the catalysts in this study by synthesizing uniform NCs in solution. With Pt alloys of $\mathrm{Cu}$ and $\mathrm{Zn}$, the uniformity will be less important, given that $\mathrm{Cu}$ and $\mathrm{Zn}$ are not active for the reaction of DMF. In this sense, alloy catalysts based on $\mathrm{Cu}$ and $\mathrm{Zn}$ could be easier to synthesize.

The fact that various Pt alloys show good selectivities raises a number of interesting questions. First, would other alloys, including ones that do not include noble metals, also show high selectivity? Second, can one generalize the high HDO selectivity for HMF that is observed with the Pt alloys to HDO reactions with other reactants, such as those one might associate with lignin? These will be interesting questions to address in the future.

\section{CONCLUSION}

Carbon-supported, monometallic Pt and Ni catalysts exhibit relatively low selectivity, less than 50\%, for DMF in the HDO reaction of HMF because DMF is converted to ring-opened or ring-hydrogenated byproducts. On the other hand, $\mathrm{Zn}$ and $\mathrm{Cu}$ catalysts are not active for HDO reactions. However, catalysts based on bimetallic Pt alloys with $\mathrm{Ni}, \mathrm{Zn}$, or $\mathrm{Cu}$ show significantly higher selectivity to DMF, up to $98 \%$. With Pt-Ni alloys, controlling the local composition is critically important for achieving high DMF yields due to the non-selectivity of the pure metals. Even though the effects of $\mathrm{Ni}, \mathrm{Zn}$, and $\mathrm{Cu}$ on $\mathrm{Pt}$ are expected to be very different, it is likely that each of the alloys modifies the bonding of DMF so as to prevent the furan ring from lying down on the surface. This appears to be the critical factor in achieving high selectivity for HDO of HMF.

\section{ACKNOWLEDGEMENT}

We acknowledge support from the Catalysis Center for Energy Innovation, an Energy Frontier Research Center funded by the U.S. Department of Energy, Office of Science, Office of Basic Energy Sciences under Award no. DE-SC0001004. 


\section{REFERENCES}

[1] T. Wang, M.W. Nolte, B.H. Shanks, Green Chem. 16 (2014) 548-572.

[2] M. Dashtban, A. Gilbert, P. Fatehi, RSC Adv. 4 (2014) 2037-2050.

[3] A.I. Torres, P. Daoutidis, M. Tsapatsis, Energy Environ. Sci. 3 (2010) 1560-1572.

[4] C.L. Williams, C.-C. Chang, P. Do, N. Nikbin, S. Caratzoulas, D.G. Vlachos, R.F. Lobo, W. Fan, P.J. Dauenhauer, ACS Catal. 2 (2012) 935-939.

[5] M. Chidambaram, A.T. Bell, Green Chem. 12 (2010) 1253-1262.

[6] T. Thananatthanachon, T.B. Rauchfuss, Angew. Chem. Int. Ed. 49 (2010) 6616-6618.

[7] J. Jae, W. Zheng, R.F. Lobo, D.G. Vlachos, ChemSusChem 6 (2013) 1158-1162.

[8] J. Luo, L. Arroyo-Ramírez, J. Wei, H. Yun, C.B. Murray, R.J. Gorte, Appl. Catal. Gen. 508 (2015) 86-93.

[9] S. Sitthisa, W. An, D.E. Resasco, J. Catal. 284 (2011) 90-101.

[10] G.-H. Wang, J. Hilgert, F.H. Richter, F. Wang, H.-J. Bongard, B. Spliethoff, C.

Weidenthaler, F. Schüth, Nat. Mater. 13 (2014) 293-300.

[11] J. Luo, H. Yun, A. Mironenko, K. Goulas, M. Monai, J. D. Lee, C. Wang, P. Fornasiero,

D. G. Vlachos, C. B. Murray, R. J. Gorte, ACS Catal. 6 (2016) 4095-4104.

[12] J.R. McManus, E. Martono, J.M. Vohs, ACS Catal. 3 (2013) 1739-1750.

[13] D. Shi, J.M. Vohs, ACS Catal. 5 (2015) 2177-2183.

[14] W. Yu, K. Xiong, N. Ji, M.D. Porosoff, J.G. Chen, J. Catal. 317 (2014) 253-262.

[15] S. Sitthisa, T. Pham, T. Prasomsri, T. Sooknoi, R.G. Mallinson, D.E. Resasco, J. Catal. 280 (2011) 17-27.

[16] S. Sitthisa, T. Sooknoi, Y. Ma, P.B. Balbuena, D.E. Resasco, J. Catal. 277 (2011) 1-13.

[17] K. Ahrenstorf, O. Albrecht, H. Heller, A. Kornowski, D. Görlitz, H. Weller, Small 3 (2007) 271-274.

[18] C.B. Murray, S. Sun, H. Doyle, T. Betley, MRS Bull. 26 (2001) 985-991.

[19] Y. Yu, W. Yang, X. Sun, W. Zhu, X.-Z. Li, D.J. Sellmyer, S. Sun, Nano Lett. 14 (2014) 2778-2782.

[20] Paul A. Heiney, Comm. Powder Diffr. Newsl. 32 (2005) 9-11.

[21] M. Cargnello, C. Chen, B.T. Diroll, V.V.T. Doan-Nguyen, R.J. Gorte, C.B. Murray, J. Am. Chem. Soc. 137 (2015) 6906-6911. 
[22] J. Luo, L. Arroyo-Ramírez, R.J. Gorte, D. Tzoulaki, D.G. Vlachos, AIChE J. 61 (2015) 590-597.

[23] A.R. Denton, N.W. Ashcroft, Phys. Rev. A 43 (1991) 3161-3164.

[24] Y. Kang, X. Ye, C.B. Murray, Angew. Chem. Int. Ed. 49 (2010) 6156-6159.

[25] Y. Holade, C. Morais, K. Servat, T.W. Napporn, K.B. Kokoh, Phys Chem Chem Phys 16 (2014) 25609-25620. 


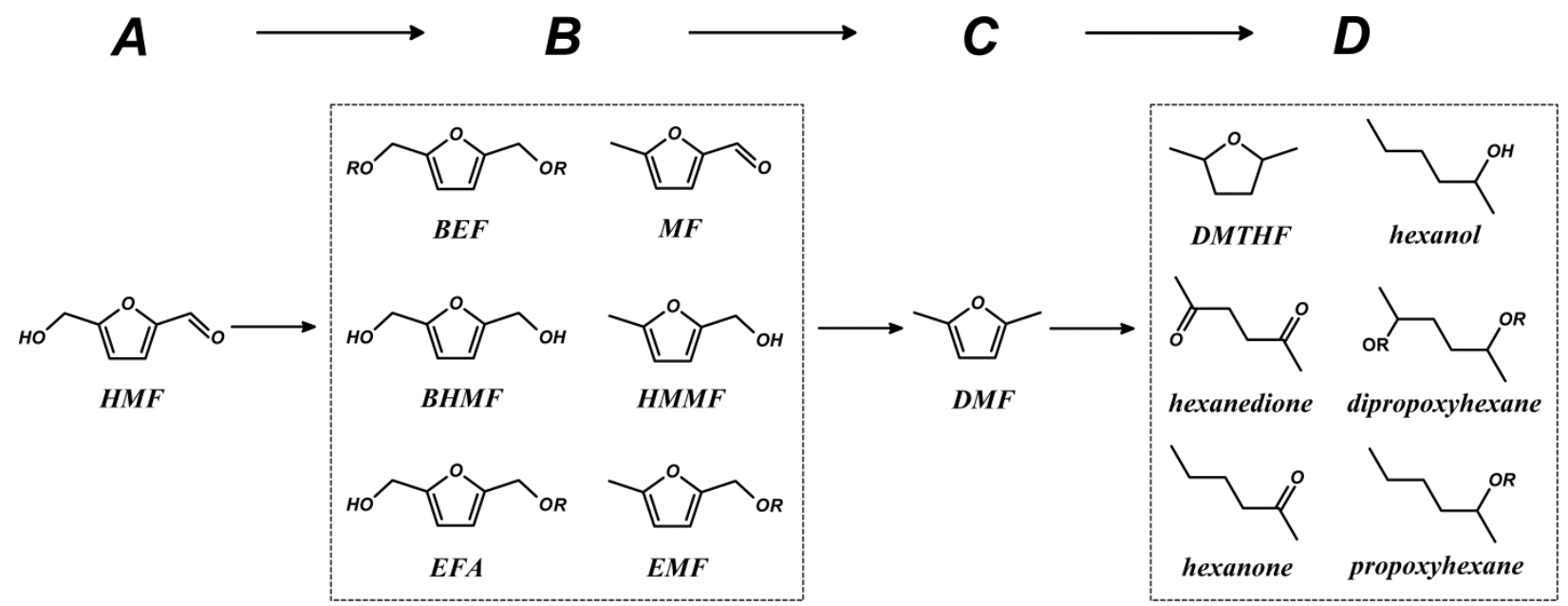

Scheme 1. Reaction network for HDO of HMF using alcohols as solvent.

A 

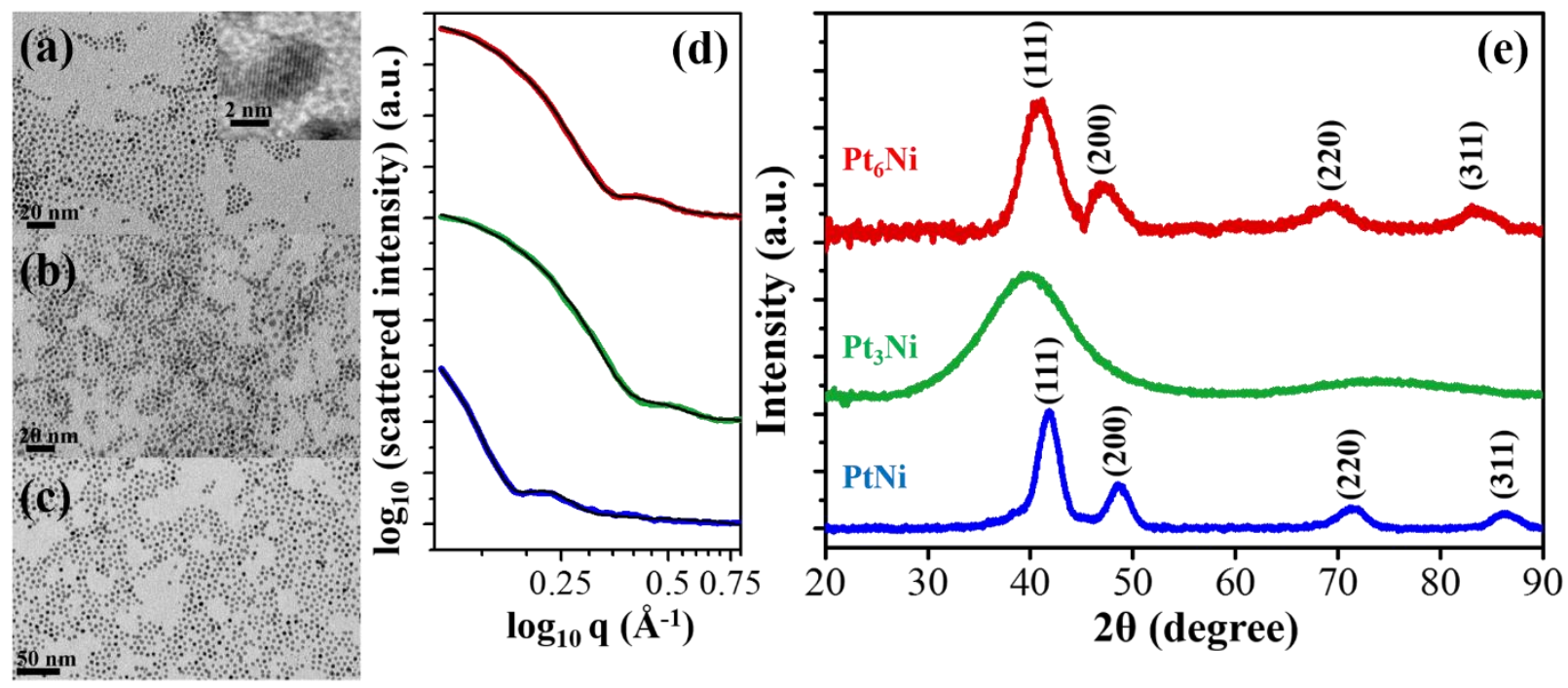

Figure 1. The TEM images of (a) $\mathrm{Pt}_{6} \mathrm{Ni}$, (b) $\mathrm{Pt}_{3} \mathrm{Ni}$ and (c) PtNi NCs, the corresponding (d) SAXS patterns and (e) XRD patterns. Inset in (a) shows the HRTEM image of $\mathrm{Pt}_{6} \mathrm{Ni}$ NCs. The black lines in (d) represent the simulated fits for the size of the catalyst. 

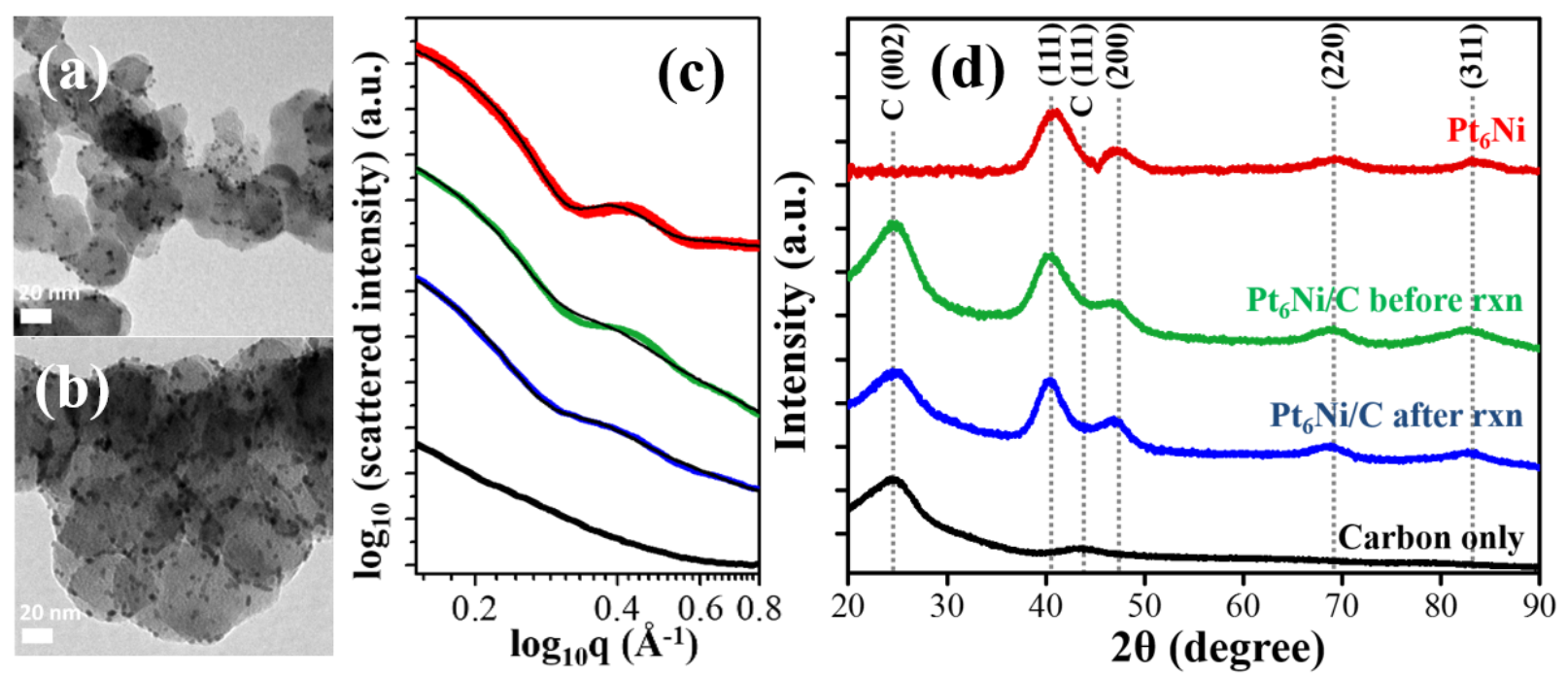

Figure 2. The TEM images of $10-\mathrm{wt} \% \mathrm{Pt}_{6} \mathrm{Ni} \mathrm{NCs}$ on carbon support (a) before and (b) after reaction. (c) SAXS patterns of $\mathrm{Pt}_{6} \mathrm{Ni} \mathrm{NCs}$ in solution (red), 10-wt\% $\mathrm{Pt}_{6} \mathrm{Ni} \mathrm{NCs}$ on carbon support before (green) and after (blue) reaction, carbon support (black), and (d) the corresponding XRD patterns. The black lines in (c) represent the simulated fits for the size of the catalyst. 

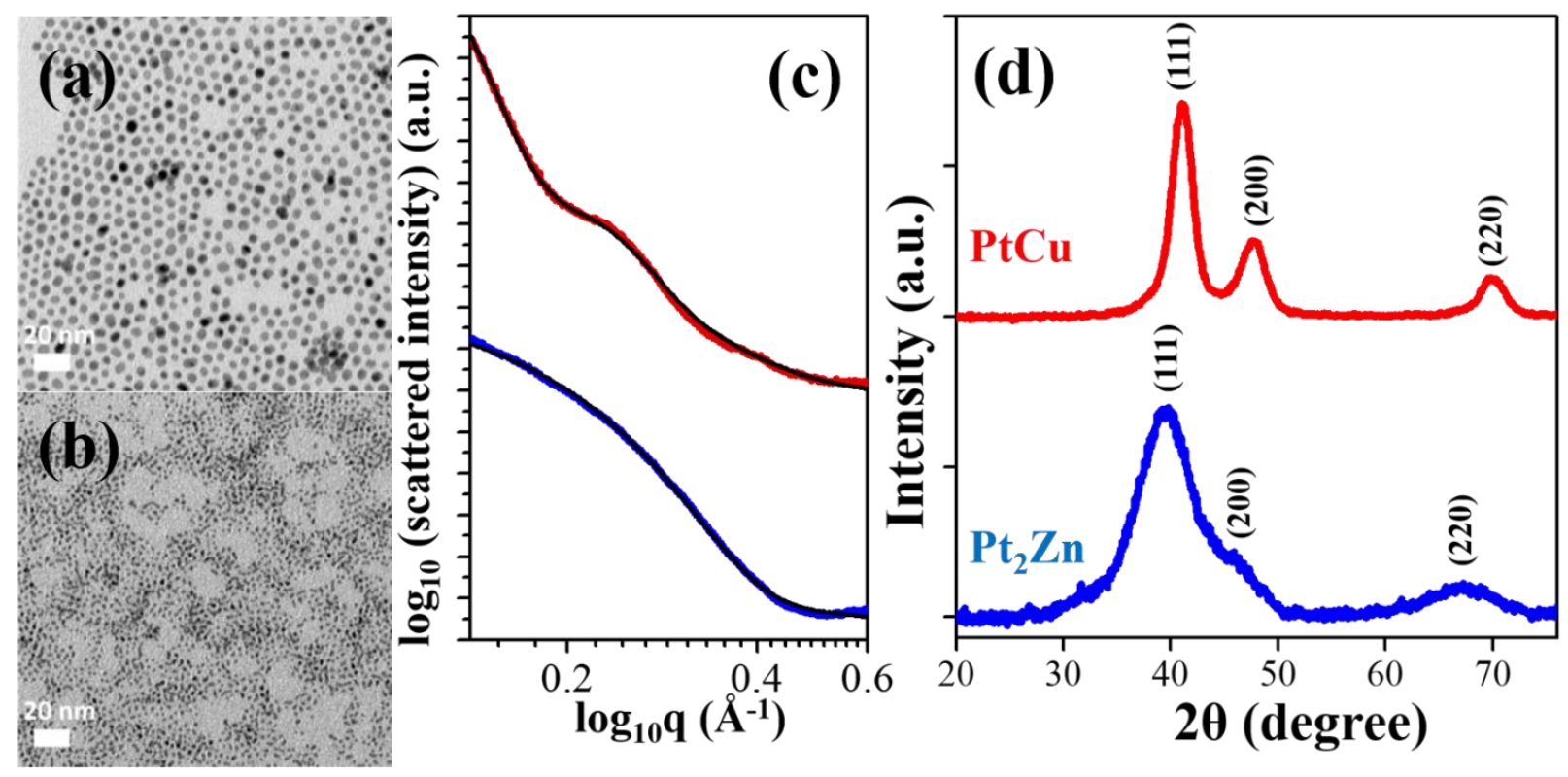

Figure 3. The TEM images of (a) $\mathrm{PtCu}$ and (b) $\mathrm{Pt}_{2} \mathrm{Zn} \mathrm{NCs}$, the corresponding (c) SAXS patterns and (d) XRD patterns. The black lines in (c) represent the simulated fits for the size of the catalyst. 


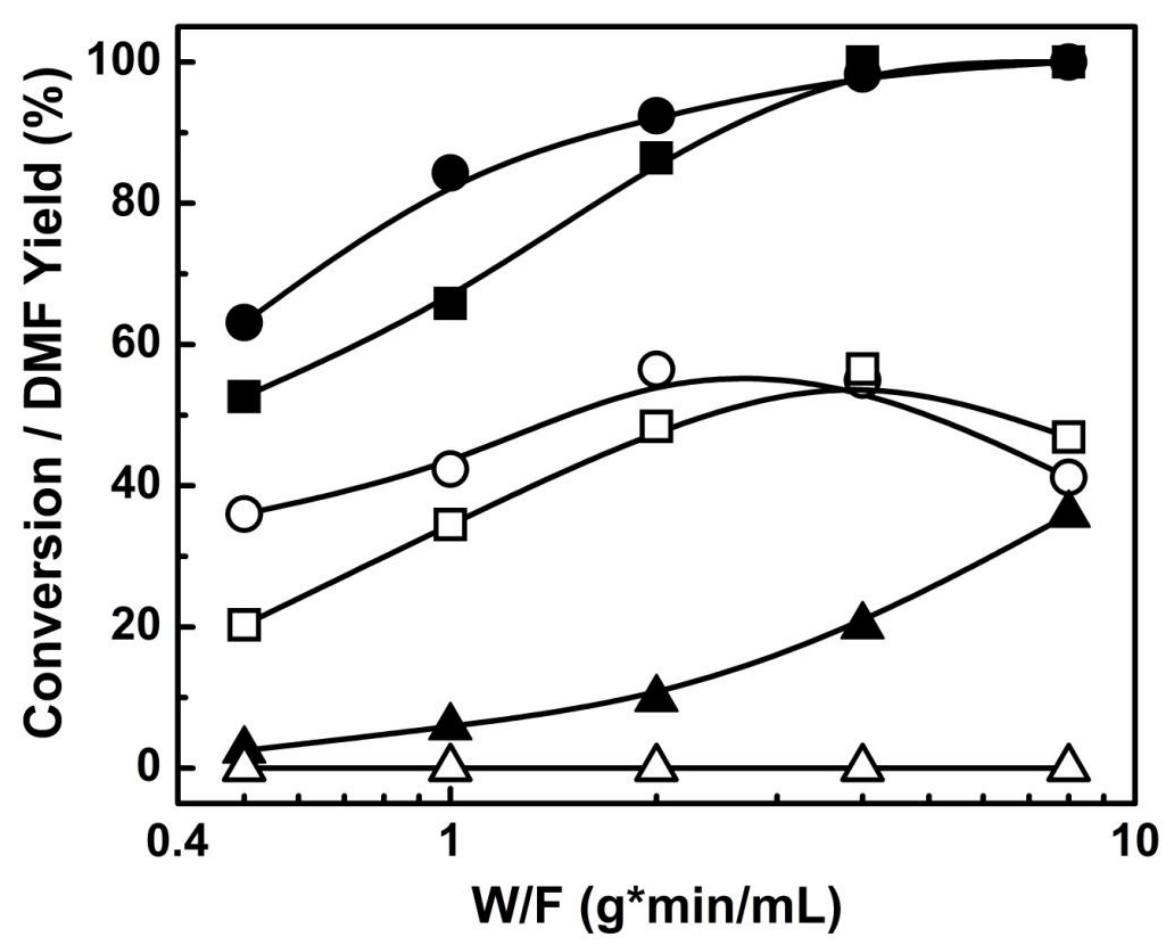

Figure 4. Conversion and DMF yield for the HDO reaction of HMF over impregnated 10-wt $\%$ monometallic catalyst, as a function of reactor space time. Reaction conditions: 33 bar and 180

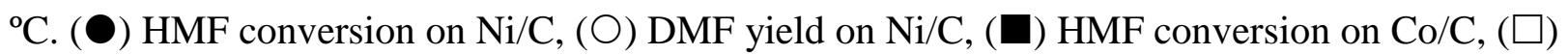
DMF yield on $\mathrm{Co} / \mathrm{C},(\boldsymbol{\Delta}) \mathrm{HMF}$ conversion on $\mathrm{Cu} / \mathrm{C},(\triangle) \mathrm{DMF}$ yield on $\mathrm{Cu} / \mathrm{C}$. Zn/C catalysts did not show any activity (not reported). 


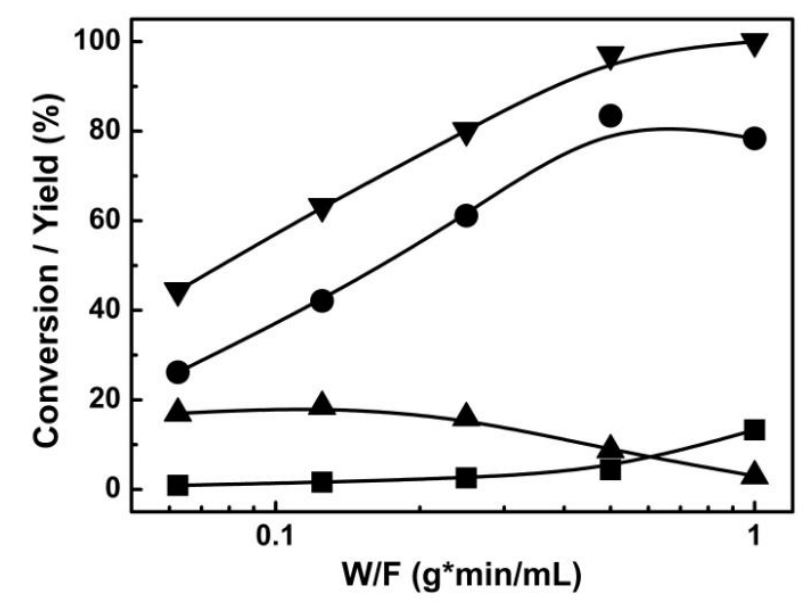

(a)

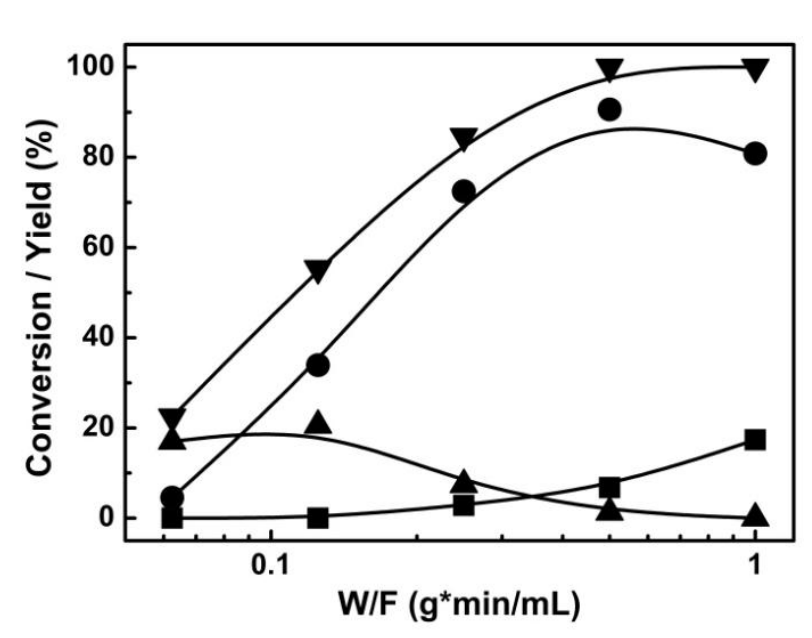

(c)

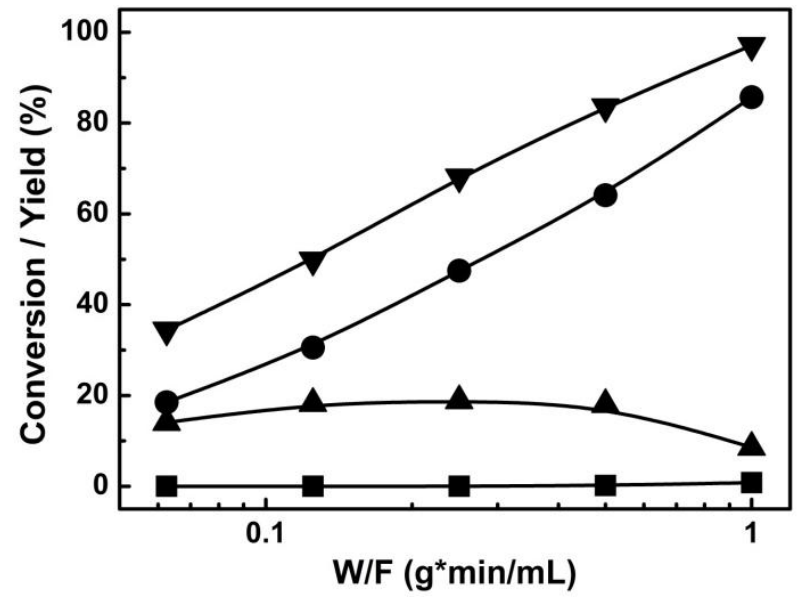

(b)

Figure 5. Conversion and product distribution for the HDO reaction of HMF over (a) 10-wt\% $\mathrm{Pt}_{6} \mathrm{Ni} / \mathrm{C}$, (b) $10-\mathrm{wt} \% \mathrm{Pt}_{3} \mathrm{Ni} / \mathrm{C}$, (c) $10-\mathrm{wt} \% \mathrm{PtNi} / \mathrm{C}$, as a function of reactor space time. Reaction conditions: 33 bar and $160{ }^{\circ} \mathrm{C}$. ( $\left.\boldsymbol{\nabla}\right) \mathrm{HMF}$ conversion, $(\boldsymbol{\Delta})$ product group B, (O) DMF, (ם) product group D 


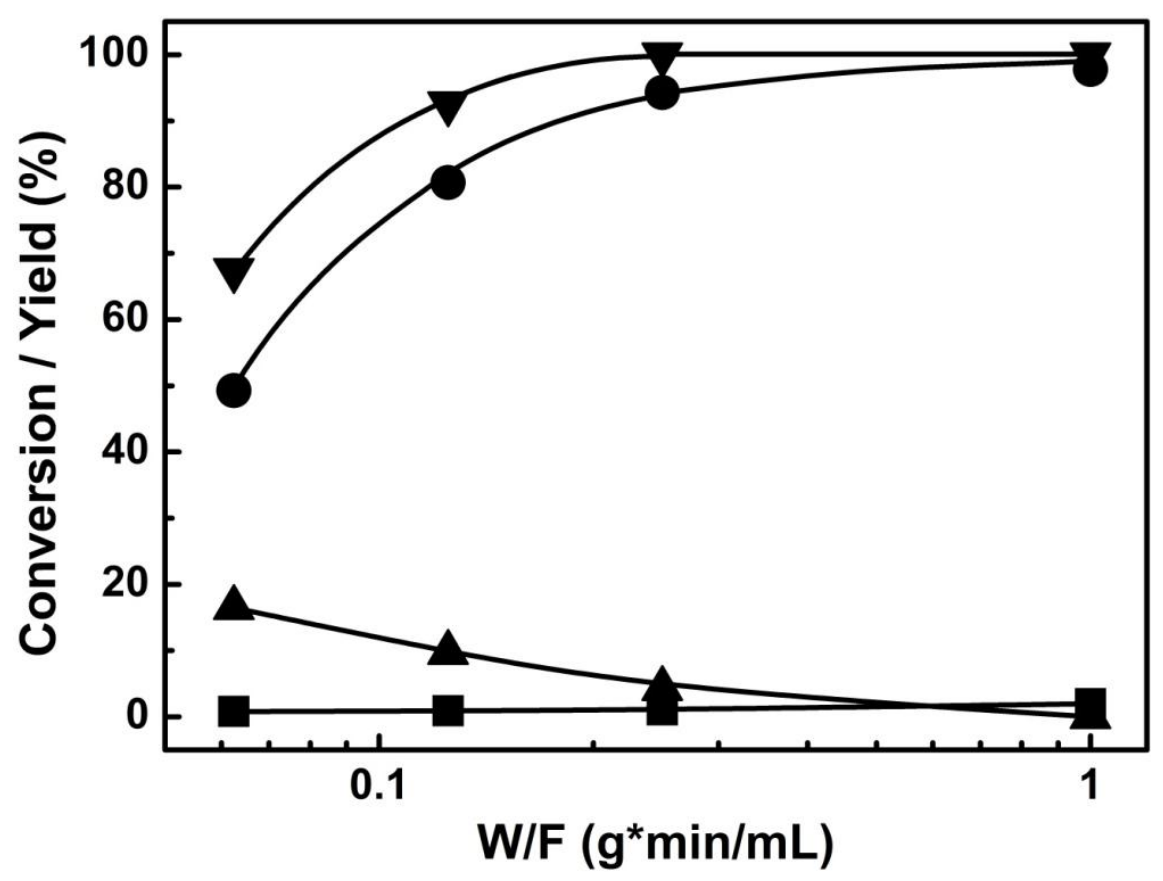

Figure 6. Conversion and product distribution for the HDO reaction of HMF over 10-wt $\%$ $\mathrm{Pt}_{3} \mathrm{Ni} / \mathrm{C}$, as a function of reactor space time. Reaction conditions: 33 bar and $200^{\circ} \mathrm{C}$. ( $\left.\boldsymbol{\nabla}\right) \mathrm{HMF}$ conversion, $(\mathbf{\Delta})$ product group B, $(\bullet) \mathrm{DMF},(\boldsymbol{\square})$ product group D 


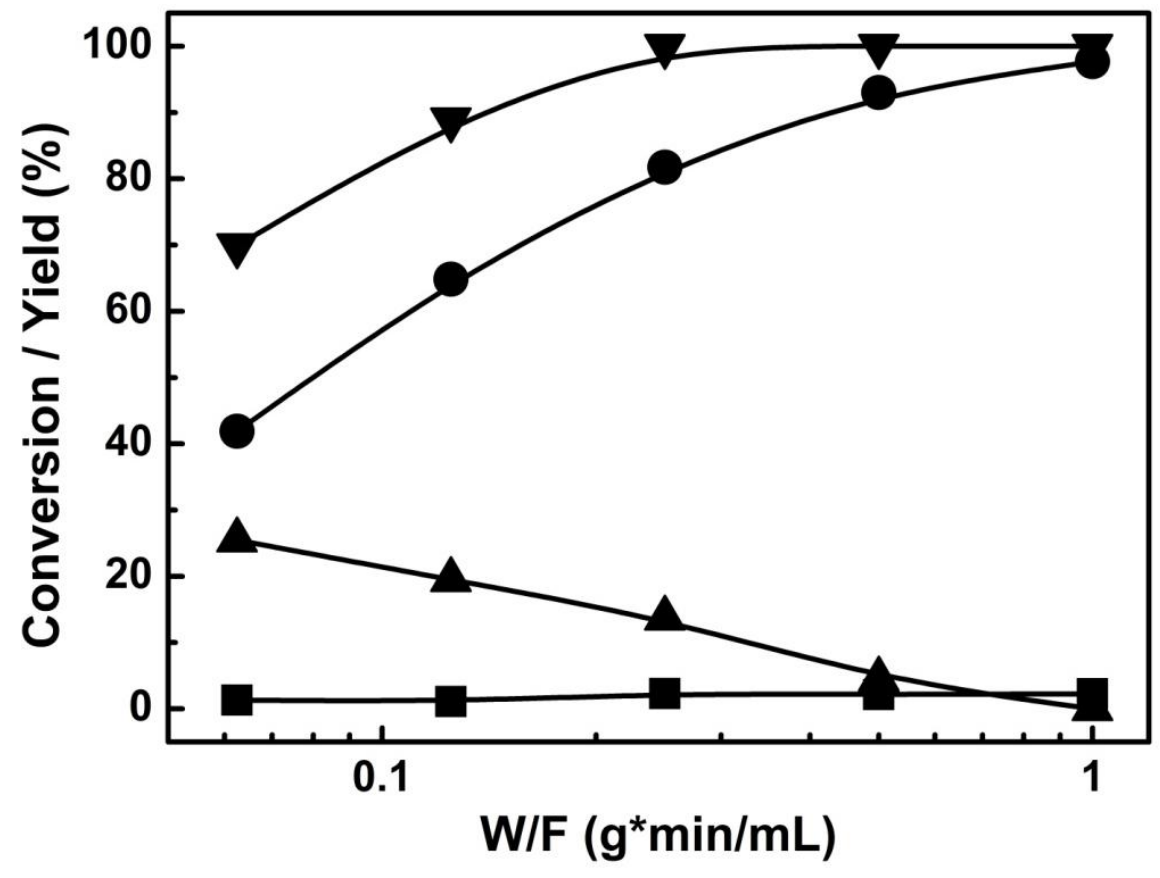

Figure 7. Conversion and product distribution for the HDO reaction of HMF over 10-wt $\%$ $\mathrm{Pt}_{2} \mathrm{Zn} / \mathrm{C}$, as a function of reactor space time. Reaction conditions: 33 bar and $200{ }^{\circ} \mathrm{C}$. ( $\left.\boldsymbol{\nabla}\right) \mathrm{HMF}$ conversion, $(\mathbf{\Delta})$ product group B, $(\bullet) \mathrm{DMF},(\boldsymbol{\square})$ product group D 


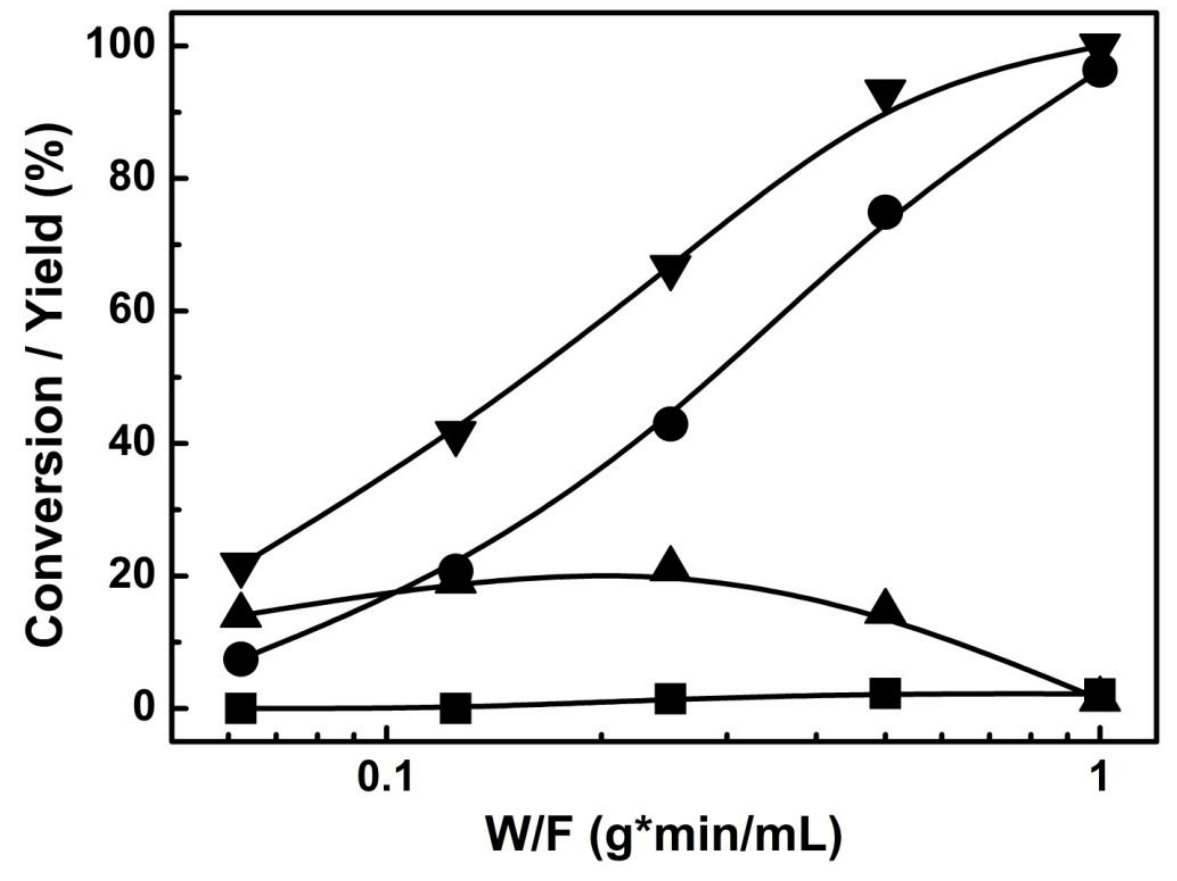

Figure 8. Conversion and product distribution for the HDO reaction of HMF over 10-wt $\%$ $\mathrm{PtCu} / \mathrm{C}$, as a function of reactor space time. Reaction conditions: 33 bar and $200^{\circ} \mathrm{C}$. ( $\left.\boldsymbol{\nabla}\right) \mathrm{HMF}$ conversion, $(\mathbf{\Delta})$ product group B, $(\bullet)$ DMF, $(\square)$ product group D 


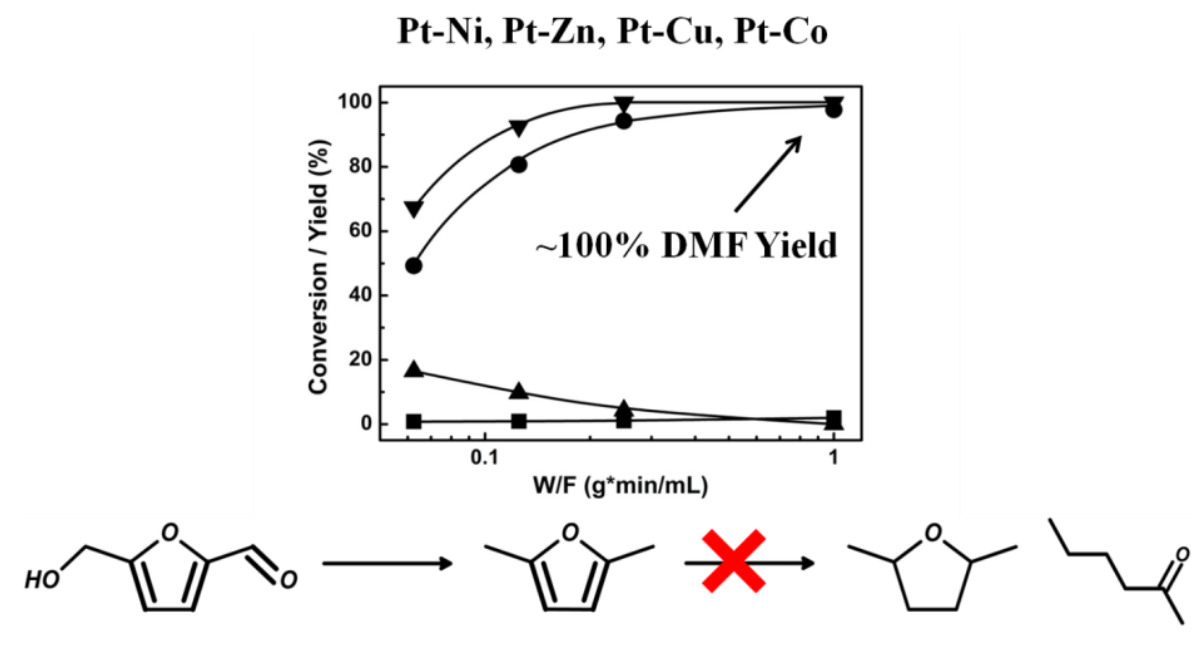

Graphic Abstract 